\title{
CRITERIA FOR INTRAVITREAL ANTIBIOTICS DURING SURGICAL REMOVAL OF INTRAOCULAR FOREIGN BODIES
}

\author{
D. V. SEAL' and C. M. KIRKNESS ${ }^{2}$ \\ Glasgow
}

\begin{abstract}
SUMMARY
Published opinion supports the early use of prophylactic antibiotics soon after presentation of a potentially contaminated intraocular foreign body (IOFB) in the posterior segment, preferably within 12 hours of trauma when the visual acuity is still good. Recommended treatment includes topical, subconjunctival, parenteral and especially intravitreal antibiotic therapy to reduce the chance of endophthalmitis. Intravitreal therapy should include gentamicin with vancomycin or clindamycin to cover Bacillus spp., since this organism is responsible for half the endophthalmitis cases and produces beta-lactamase giving resistance to penicillins and cephalosporins. Intravitreal therapy is important because systemic and topical antibiotics do not penetrate the globe in sufficient concentration to control a fulminant infection associated with damaged tissue. Early therapy is essential, as delaying treatment until endophthalmitis occurs is less likely to save useful vision. All vitreous aspirated, plus pus if present, and the IOFB should be cultured for bacteria and fungi to identify pathogens and gain antibiotic sensitivities. The prevention of IOFB-associated endophthalmitis requires early recognition of the IOFB and enthusiastic antibiotic therapy at the time of its removal.
\end{abstract}

Retained intraocular foreign bodies (IOFB) following penetrating trauma may cause loss of the eye or vision from a number of mechanisms. The introduction of bacteria or fungi into the eye in conjunction with the foreign body can rapidly lead to the development of endophthalmitis. Removal of the foreign body, if undertaken early enough, may also allow removal of the microbial inoculum at the same time but, when there is delay or heavy contamination, simple extraction of the extrinsic material may not prevent endophthalmitis.

Development of endophthalmitis can occur over 24-36

From: 'Department of Bacteriology, Glasgow Royal Infirmary, Glasgow G4 OSF, and 'Tennent Institute of Ophthalmology, University of Glasgow, 38 Church Street, Glasgow G11 6NT, UK.

Correspondence to: Dr D. V. Seal, Department of Bacteriology, Glasgow Royal Infirmary, Glasgow G4 OSF, UK. hours following injury. Pain, loss of vision, lid swelling, chemosis, corneal oedema, hypopyon and vitreous cells or abscess may be found. With organisms such as Bacillus spp. and Clostridium spp. there may be leucocytosis and pyrexia. By the time this stage is reached even vitrectomy and intravitreal injection of an appropriate antibiotic will not preserve light perception in half the cases.

It is the aim of this review article to put secondary endophthalmitis into context and to discuss how this complication may be prevented by adopting a rational approach to management and antibiotic therapy.

\section{PREVALENCE AND INFECTING ORGANISMS}

Recent reviews (Table I) suggest that 56 of 707 patients $(8 \%)$ with a retained IOFB developed endophthalmitis, of whom $37(66 \%)$ lost all light perception. ${ }^{1-6}$ In addition to these prevalence series there have been a number of individual case reports (Table II) from 1970 to $19900^{7.18}$ All these reports indicate that a relatively small range of organisms accounts for nearly all cases of endophthalmitis, with Bacillus spp. being commonly reported in the American literature.

\section{Type of IOFB Causing Infection}

Any IOFB may be contaminated, but in particular steel fragments from hammering metal or those contaminated with soil (e.g. following horticultural and agricultural accidents) are at high risk.

\section{Range of Organisms}

Bacillus spp. which are present in soil may cause posttraumatic endophthalmitis with or without retention of a foreign body. The presence of an IOFB and its tract of traumatised tissue are likely to increase the chances of infection. Following removal of the IOFB, residual dead tissue may yet form the nidus for ongoing infection. $B$. cereus appears to be the most virulent species due to a unique exotoxin, enterotoxins and proteolytic enzymes that it produces. ${ }^{18}$ Other species, such as $B$. licheniformis, 
Table I. Risk (prevalence rate) for endophthalmitis occurring with IOFBs (1984-1990)

\begin{tabular}{|c|c|c|}
\hline Reference & $\begin{array}{c}\text { Occurrence of } \\
\text { endophthalmitis } \\
\text { with an IOFB }\end{array}$ & $\begin{array}{l}\text { Loss of light } \\
\text { perception in those } \\
\text { with endophthalmitis }\end{array}$ \\
\hline Brinton et al. (1984)' & $11 / 103(10.7 \%)$ & $8 / 11(72.7 \%)$ \\
\hline Williams et al. $(1988)^{2}$ & $11 / 105(10.5 \%)$ & $5 / 11(45.5 \%)$ \\
\hline \multicolumn{3}{|l|}{ Behrens-Baumann and } \\
\hline Praetorius $(1989)^{3}$ & $14 / 297 \quad(4.7 \%)$ & $12 / 14(85.7 \%)$ \\
\hline \multicolumn{3}{|l|}{ Punnonen and } \\
\hline Laatikainen $(1989)^{4}$ & $(7.0 \%)$ & $4 / 7 \quad(57.1 \%)$ \\
\hline Boldt et al. (1989) & $13 / 80 \quad(16.0 \%)$ & $8 / 13(61.5 \%)$ \\
\hline Mieler et al. $(1990)^{6}$ & $0 / 27 \quad(<1.0 \%)^{\mathrm{a}}$ & 0 \\
\hline Overall results & $56 / 707 \quad(7.9 \%)$ & $37 / 56(66 \%)$ \\
\hline
\end{tabular}

${ }^{a}$ Prophylactic intravitreal antibiotic was given in 3 cases, of which 2 had Bacillus spp. isolated from the IOFB. Three other IOFBs grew Staphylococcus epidermidis (2) and Streptococcus group D (1).

which are thought to be less virulent may also cause endophthalmitis in our experience. Infection with Bacillus spp. nearly always leads to loss of light perception and there are only two reports of useful vision being retained after infection with this organism. ${ }^{18}$ Moreover in these cases the infection developed after elective surgery and not after trauma. Early recognition may have been germane to the outcome.

Bacteria and fungi were reliably reported in three of the prevalence series reviewed, ${ }^{1,2,5}$ and are listed in Table III. Bacillus spp. were most frequently isolated at $43 \%$ overall, staphylococci at $31 \%$, coliforms at $9 \%$ and streptococci and fungi each at 3\%. Clostridium spp. were not isolated. These figures contrast with isolates listed in the case reports in Table II, where frequency is biased by reporting of worst outcomes. On these occasions Bacillus spp. have been reported from $67 \%$ of cases while other bacteria and fungi had a similar distribution to the prevalence series (Table II) - apart from Staphylococcus aureus which was inexplicably absent.

Clostridium spp. have been reported worldwide as causing endophthalmitis and associated gas gangrene in 63 cases, which have usually involved contamination with soil. ${ }^{12}$ Crock et al. ${ }^{12}$ reported a case of bilateral perforating injury in a worker who struck gelignite in a trench. One eye was lost but the other was saved by thorough toilet including the removal of mud from the anterior chamber and surface of the iris; culture of the aspirated material yielded $C$. perfringens. The authors speculate that early removal of all foreign material and intraocular antibiotics may have been beneficial to the outcome. They argue, in addition, that removal of the avascular vitreous reduces the size of the inoculum. The low redox potential necessary for growth of Clostridium spp. is found both in vitreous and lens and makes them an ideal culture medium.

\section{MANAGEMENT AND THERAPY}

Brinton et al.,' Mieler et al. ${ }^{6}$ and Hemady et al. ${ }^{18}$ have argued for effective prophylaxis at the time of IOFB removal from the posterior segment, particularly when there is a high likelihood of contamination and the visual acuity is good. If reliable prediction of contamination could be made, intravitreal antibiotic prophylaxis could be given selectively. Mieler et $a l^{6}{ }^{6}$ attempted to predict which IOFBs were contaminated with Bacillus spp. and treated patients prophylactically on the basis that infection with this organism carries the worst prognosis. They gave prophylaxis to three patients, from two of whom they successfully cultured Bacillus spp.; neither developed endophthalmitis. Three other IOFBs yielded streptococci or staphylococci but the eyes did not develop endophthalmitis despite the absence of antibiotic prophylaxis.

An alternative approach that might be considered more prudent is to provide intravitreal prophylaxis for all patients at the time of IOFB removal. Since infection is expected to occur in 1 in 12 patients, not adopting this approach seems difficult to justify.

The choice of antibiotic regime is important. Boldt et $a l .{ }^{5}$ suggested that empirical regimes widely in use tend to reflect urban practice rather than rural experience, where injuries are common but may produce a different spectrum of organisms. A quarter of their cases showed polymicrobial infection, with mixed bacilli in three and mixed fungi in one. This situation may also occur in agricultural injuries without retained IOFBs. ${ }^{19}$ Bacillus spp. were not found more commonly, however, in Boldt's rural-based series $(46 \%)$ than was expected in urban practice $(41 \%)$, due to the ubiquitous presence of this organism, or its spores, in dirt.

Table II. Bacteria and fungi reported as causing IOFB-associated endophthalmitis in 1970-1990 as case reports: vitreous samples

\begin{tabular}{|c|c|c|c|c|c|c|c|}
\hline Reference & Bacillus & S. epi & S. aureus & GNR & Strep. & Fungus & Clost \\
\hline Levitt and Stamm $(1970)^{7}$ & 0 & 0 & 0 & 0 & 0 & 0 & 1 \\
\hline Peyman et al. $(1980)^{8}$ & 0 & 1 & 0 & 1 & 0 & 1 & 1 \\
\hline Rowsey et al. $(1982)^{10}$ & 3 & 0 & 0 & 1 & 0 & 0 & 0 \\
\hline Ho et al. $(1982)^{11}$ & 4 & 0 & 0 & 0 & 0 & 0 & 0 \\
\hline Crock et al. $(1985)^{12}$ & 0 & 0 & 0 & 0 & 0 & 0 & 2 \\
\hline Davey and Tauber $(1987)^{1.3}$ & 1 & 0 & 0 & 0 & 0 & 0 & 0 \\
\hline Affeldt et al. $(1987)^{14}$ & 3 & 2 & 0 & 2 & 1 & 0 & 0 \\
\hline Schemmer and Driebe $(1987)^{15}$ & 2 & 0 & 0 & 0 & 0 & 0 & 0 \\
\hline Thurn and Goodman $(1988)^{16}$ & 1 & 0 & 0 & 0 & 0 & 0 & 0 \\
\hline Al-Hemidan et al. $(1989)^{17}$ & 1 & 0 & 0 & 0 & 0 & 0 & 0 \\
\hline Hemady et al. $(1990)^{18}$ & 4 & 0 & 0 & 0 & 0 & 0 & 0 \\
\hline Overall results $(\%)$ & 67 & 8 & 0 & 11 & 3 & 3 & 8 \\
\hline
\end{tabular}

Key: S. epi, Staphylococcus epidermidis; S. aureus, Staphylococcus aureus; GNR, Gram-negative bacteria; Strep., streptococci; Clost., Clostridium perfringens. 
Table III. Bacteria and fungi reported as causing IOFB-associated endophthalmitis in $1984-1990$ prevalence surveys

\begin{tabular}{|c|c|c|c|c|c|c|c|}
\hline Reference & Bacillus & S. epi & S. aureus & GNR & Strep. & Fungus & Others \\
\hline Brinton et al. (1984)' & 5 & 2 & 3 & 1 & 0 & 0 & 0 \\
\hline Williams et al. $(1988)^{2}$ & 4 & 4 & 0 & 1 & 1 & 0 & 1 \\
\hline Boldt et al. (1989) & 6 & 1 & 1 & 1 & 0 & 1 & 3 \\
\hline Overall results (\%) & 43 & 20 & 11 & 9 & 3 & 3 & 11 \\
\hline
\end{tabular}

Key: S. epi, Staphylococcus epidermidis; S. aureus, Staphylococcus aureus; GNR, Gram-negative bacteria; Strep., streptococci.

Suggested Protocol for Management of Perforating Injury with Retained IOFB

The authors agree with Mieler et al. ${ }^{6}$ and Hemady et al. ${ }^{18}$ who recommend that surgery be undertaken as early as practicable.

Anterior segment. The IOFB should be cultured in the laboratory together with any pus present or tissue removed from the eye. Pus should be stained as previously described for bacteria and fungi. ${ }^{19}$ Subconjunctival gentamicin $40 \mathrm{mg}$ plus clindamycin $34 \mathrm{mg}$ should be given at the end of surgery. Topical therapy can then be continued with frequent fortified gentamicin $(1.5 \%)$ and clindamycin $(2 \%)$ drops. Where there is contamination with vegetable matter additional topical antifungal prophylaxis, e.g. $5 \%$ natamycin drops, $0.15 \%$ amphotericin drops or $1 \%$ clotrimazole in arachis oil, should be given. ${ }^{20}$ These antifungal drugs cannot be given subconjunctivally.

Posterior segment. The use of subconjunctival antibiotics is of dubious value since they may not penetrate the posterior segment of an intact eye in adequate concentration; where there is extensive disorganisation, however, antibiotics administered by the subconjunctival route may reach the vitreous. Since this penetration is unpredictable the use of intravitreal antibiotics is recommended. Here the potential toxicity must be weighed against the possible benefit.

The antibiotic regime suggested by Brinton et al. ${ }^{1}$ in 1984 may still be useful:

intravitreal gentamicin $100 \mu \mathrm{g}+$ cephazolin $2.5 \mathrm{mg}$ subconjunctival gentamicin $40 \mathrm{mg}$ + clindamycin $34 \mathrm{mg}$ intravenous gentamicin $2-5 \mathrm{mg} / \mathrm{kg}$ per day (monitor dose)

+ cephazolin $3 \mathrm{~g} /$ day

topical gentamicin $1.5 \%+$ cephazolin $5 \%$

but vancomycin or clindamycin may be substituted advantageously for cephazolin since Bacillus spp. produce betalactamase and are resistant to cephalosporins; they are fuily sensitive to gentamicin and vancomycin and often to clindamycin. ${ }^{21,22}$ It is appropriate to consider Bacillus spp. in particular since they are expected to cause $43 \%$ of endophthalmitis cases. The authors concede that data from the United Kingdom are sparse but experience suggests that the spectrum of infection is similar.

Dosages for vancomycin and clindamycin are as follows:

$\begin{array}{lcc}\text { Intravitreal } & 1-2 \mathrm{mg} & 0.3-1.0 \mathrm{mg} \\ \text { Subconjunctival } & 25 \mathrm{mg} & 34 \mathrm{mg} \\ \text { Intravenous } & 2 \mathrm{~g} / \text { day (monitor) } & 1.0-2.5 \mathrm{~g} / \mathrm{day} \\ \text { Topical } & 2-5 \% & 2 \%\end{array}$

The combination of gentamicin and vancomycin gives broad spectrum prophylaxis against all bacteria listed in Tables II and III. The intravitreal dose of gentamicin may be increased to $200 \mu \mathrm{g}$ maximum but care must be taken with the dilution to avoid errors. Higher doses have been used but may be associated with toxicity. Dilution errors occur with the 'dead space' in $1 \mathrm{ml}$ syringes, when concentrations can vary from $56 \%$ to $168 \%$ of the required dose. ${ }^{23}$ Constituents should be mixed carefully in a separate vessel. If there is suspicion of fungal contamination, and for agricultural or horticultural injuries, $5 \mu \mathrm{g}$ $(0.005 \mathrm{mg})$ amphotericin should be given intravitreally in addition.

Future therapy may include the fluoroquinalone group of antibiotics which have broad spectrum activity against some of the organisms listed in Tables II and III. They have good activity against Bacillus spp. ${ }^{21,22}$ and Gramnegative rods but have marginal activity against streptococci and none against fungi. Intraocular Bacillus spp. are not expected, however, to respond to intravenous ciprofloxacin therapy since only $10-30 \%$ penetrates the eye. Ciprofloxacin has been given intravitreally in rabbits but is rapidly cleared within 24 hours by the retinal pump mechanism, whereas gentamicin remains active for 48 hours. ${ }^{24}$ Ciprofloxacin resistance is recognised in our laboratory, so combination with another antibiotic such as vancomycin is required.

\section{CONCLUSION}

It is not current practice to use intraocular antibiotics as prophylaxis for removal of an IOFB from the posterior segment at the time of surgery, since only $8 \%$ of patients are expected to develop an endophthalmitis. This approach is questionable as half of those who develop endophthalmitis can be expected to lose useful vision. Prophylaxis with intravitreal antibiotics at the time of surgery is prudent. It should be considered mandatory if the type of accident from which the IOFB injury has arisen, such as hammering metal in dirty surroundings or a horticultural injury, has been associated before with endophthalmitis caused in particular by Bacillus spp. ${ }^{5.11 .18}$

Key words: Bacillus spp., Endophthalmitis, Intraocular foreign bodies, Prophylaxis.

\section{REFERENCES}

1. Brinton GS, Topping TM, Hyndiuk RA: Posttraumatic endophthalmitis. Arch Ophthalmol 1984, 102: 547-50.

2. Williams DF, Mieler WF, Abrams GW, Lewis H: Results 
and prognostic factors in penetrating ocular injuries with retained intraocular foreign bodies. Ophthalmology 1988, 95: $911-16$.

3. Behrens-Baumann W, Praetorius G: Intraocular foreign bodies. Ophthalomologica 1989, 198: 84-8.

4. Punnonen E, Laatikainen L: Prognosis of perforating eye injuries with intraocular foreign bodies. Acta Ophthalmol 1989, 66: 483-91.

5. Boldt HC, Pulido JS, Blodi CF, Folk JC, Weingeist TA: Rural endophthalmitis. Ophthalmology 1989, 96: 1722-6.

6. Mieler WF, Ellis MK, Williams DF, Han DP: Retained intraocular foreign bodies and endophthalmitis. Ophthalmology 1990, 97: 1532-8.

7. Levitt JM, Stamm J: Clostridium prefringens panophthalmitis. Arch Ophthalmol 1970, 84: 227-8.

8. Peyman GA, Carroll CP, Raichard M: Prevention and management of traumatic endophthalmitis. Ophthalmology 1980, 87: 320-4.

9. O'Day DM, Smith RS, Gregg CR, Turnbull PCB, Head WS, Ives JA, Ho PC: The problem of Bacillus species infection with special emphasis on the virulence of Bacillus cereus. Ophthalmology 1981, 88: 833-8.

10. Rowsey JJ, Newsom DL, Sexton DJ, Harms WK: Endophthalmitis: current approaches. Ophthalmology 1982, 89: 1055-65.

11. Ho PC, O'Day DM, Head WS: Fulminating panophthalmitis due to exogenous infection with Bacillus cereus: report of 4 cases. Br J Ophthalmol 1982, 66: 205-8.

12. Crock GW, Heriot WJ, Janakiraman P, Weiner JM: Gas gangrene infection of the eyes and orbits. Br J Ophthalmol 1985, 69: 143-8.

13. Davey RT, Tauber WB: Posttraumatic endophthalmitis: the emerging role of Bacillus cereus infection. Rev Infect Dis 1987, 9: 110-23.

14. Affeldt JC, Flynn HW, Forster RK: Microbial endophthalmitis resulting from ocular trauma. Ophthalmology 1987, 94: 407-13.

15. Schemmer GB, Driebe WT: Posttraumatic Bacillus cereus endophthalmitis. Arch Ophthalmol 1987, 105: 342-4.

16. Thurn JR, Goodman JL: Posttraumatic ophthalmitis due to Bacillus licheniformis. Am J Med 1988, 85: 708-9.

17. Al-Hemidan A, Byrne-Rhodes KA, Tabbara KF: Bacillus cereus panophthalmitis associated with intraocular gas bubble. Br J Ophthalmol 1989, 73: 25-8.

18. Hemady R, Zaltas M, Paton B, Foster CS, Baker AS: Bacillus-induced endophthalmitis: new series of 10 cases and review of the literature. Br J Ophthalmol 1990, 74: 26-9.

19. Ficker L, Kirkness CA, McCartney A, Seal DV: Microbial keratitis: the false negative. Eye 1991, 5: 549-59.

20. Kirkness CM, Seal DV, Clayton YM, Punithalingam E: Sphaeropsis subglobosa keratomycosis: first reported case. Cornea 1991, 10: 85-9.

21. Weber DJ, Saviteer SM, Rutala WA, Thomann CA: In-vitro susceptibility of Bacillus sp. to selected antimicrobial agents. Antimicrob Ag Chemother 1988, 32: 642-5.

22. Kervick GN, Flynn Jnr HW, Alfonso E, Miller D: Antibiotic therapy for Bacillus sp. infections. Am J Ophthalmol 1990, 110: $683-7$.

23. Noske W: Inaccuracy in preparation of intravitreal solutions. Arch Ophthalmol 1986, 104: 1748-9.

24. Davey PG, Barza M, Stuart M: Dose response of experimental Pseudomonas endophthalmitis to ciprofloxacin, gentamicin, and imipenem: evidence for resistance to late treatment of infections. J Infect Dis 1987, 155: 518-25. 